\title{
Telomerase activity in pancreatic endocrine tumours: a potential marker for malignancy
}

\author{
K Y Lam, C Y Lo, S T Fan, J M Luk
}

\begin{abstract}
Aims-Telomerase activation is known to be a common event in human cancer and may be a useful marker for malignancy. In general, the histological features of pancreatic endocrine tumours cannot be used to determine their malignant potential. The aim of this study was to investigate the role of testing telomerase activity in pancreatic endocrine tumours. Methods-Prospectively collected fresh frozen tissue specimens from 10 patients with pancreatic endocrine tumours (nine insulinomas, one adrenocorticotrophin producing pancreatic endocrine tumour) were examined by a highly sensitive polymerase chain reaction (PCR) based telomerase repeat protocol (TRAP). Results-Of the 10 pancreatic endocrine tumours, three had telomerase activity. The positive cases included two frankly malignant tumours with liver metastases and one pancreatic endocrine tumour occurring in the setting of multiple endocrine neoplasia type 1 . The latter had an infiltrative border. Vascular and perineural tumour infiltration was noted. In the two malignant pancreatic endocrine tumours with liver metastases, telomerase activity was noted in the tumour and the adjacent morphologically non-neoplastic pancreas.

Conclusion-To our knowledge, this is the first report of the role of telomerase activity in pancreatic endocrine tumours. Telomerase activity might be useful for distinguishing between benign and malignant pancreatic endocrine tumours.

(f Clin Pathol: Mol Pathol 2000;53:133-136)
\end{abstract}

Keywords: telomerase; pancreatic endocrine tumour

Department of Pathology, University of Hong Kong Medical Center, Queen Mary Hospital, Pokfulam

Road 102, Hong Kong, SAR

K Y Lam

Department of Surgery, University of Hong Kong Medical Center

C Y Lo

S T Fan

J M Luk

Correspondence to:

Dr Lam

email: akylam@hkucc.hku.hk

Accepted 21 March 2000 shortening of these sequences is observ germ line cells.

Telomerase is an important ribonucleoprotein that acts as an enzyme for the mainte- nance of telomeres during cell division. ${ }^{2}$ It is an RNA dependent DNA polymerase that synthesises the telomeric DNA repeats by using an RNA template (termed "hTR") subunit of the telomerase holoenzyme. The enzyme is inactive in adult somatic cells, except for germ cells, activated lymphocytes, and stem cells of regenerative tissues. Raised telomerase activity has been selectively demonstrated in a large number of human tumours. ${ }^{1}$ It has generated considerable excitement for research workers and has been proposed as a potential marker for malignancy, a prognostic indicator, and a target of future anticancer strategies.

Pancreatic endocrine tumours are an uncommon type of endocrine tumour. These tumours present an important challenge to clinicians because of their hormonal manifestations, associated morbidity, and potential lethality. ${ }^{34}$ Unlike other tumours in general, it is difficult to assess the biological behaviour of pancreatic endocrine tumours based on histological studies alone. The diagnosis of malignancy usually depends on the presence of metastases. Despite the recent boom in clinical telomerase research, telomerase activity has rarely been studied in pancreatic endocrine tumours. ${ }^{5}$ In our study, we analysed the presence of telomerase activity in pancreatic endocrine tumours to evaluate the investigation of telomerase activity as a marker for predicting the biological behaviour of these tumours. Possible correlations with clinicopathological parameters were also studied.

\section{Patients and methods}

COLLECTION OF TISSUES AND PATHOLOGICAL EXAMINATION

The tissue samples were collected prospectively from patients with pancreatic endocrine tumours in the five year study period (1995 to 1999). The resection specimens were dissected when fresh. Macroscopically, the site and size (maximum dimension) of the pancreatic tumours were recorded by one of us (KYL). In each case, one representative frozen block from the tumour and one from the non-neoplastic pancreas were snap frozen in liquid nitrogen at $-70^{\circ} \mathrm{C}$ and stored until used. Other standard blocks were then taken, fixed in $10 \%$ formalin, and embedded in paraffin wax. Histological sections $(6 \mu \mathrm{m}$ thick $)$ of the paraffin wax and frozen blocks were cut and stained with haematoxylin and eosin for light microscopic analysis. The diagnoses and clinicopathological subtypes of the tumours were confirmed with immunohistochemical stains using antibodies, as in our previous study. ${ }^{6}$ The demographic data, clinical characteristics, laboratory 
Table 1 Clinicopathological features and telomerase activity in pancreatic endocrine tumours (PETs)

\begin{tabular}{|c|c|c|c|c|c|c|c|c|c|}
\hline Case/Race & Sex/Age & Site & Tumour type & Size (diameter) of PETs & $\begin{array}{l}\text { Telomerase } \\
\text { activity }\end{array}$ & $\begin{array}{l}\text { Optical } \\
\text { density }\end{array}$ & Treatment & $\begin{array}{l}\text { Follow up } \\
\text { (months) }\end{array}$ & Remarks \\
\hline 1/Chinese & $\mathrm{M} / 46$ & Head & Insulinoma & $1.5 \mathrm{~cm}$ & Negative & - & Enucleation & 52, alive, NED & \\
\hline 2/Chinese & $\mathrm{M} / 41$ & Multiple & Insulinoma & $\begin{array}{l}\text { Multiple tumors, the } \\
\text { largest one: } 6.0 \mathrm{~cm} \text { at tail }\end{array}$ & Negative & - & $\begin{array}{l}\text { Distal subtotal } \\
\text { pancreatectomy }\end{array}$ & 46 , alive NED & Had MEN 1 \\
\hline 3/Chinese & $\mathrm{F} / 43$ & Body & $\begin{array}{l}\text { Malignant ACTH } \\
\text { producing PET }\end{array}$ & $1.0 \mathrm{~cm}$ & Positive & 1.9 & Distal pancreotomy & 18, died & $\begin{array}{l}\text { Metastases in } \\
\text { liver }\end{array}$ \\
\hline 4/Chinese & $\mathrm{M} / 22$ & Multiple & Insulinoma & $\begin{array}{l}\text { Multiple tumours, the } \\
\text { largest one: } 1.0 \mathrm{~cm} \text { at tail }\end{array}$ & Positive & 1.9 & $\begin{array}{l}\text { Distal subtotal } \\
\text { pancreatectomy }\end{array}$ & 36, alive NED & Had MEN 1 \\
\hline 5/Indian & $\mathrm{F} / 49$ & Tail & Insulinoma & $1.5 \mathrm{~cm}$ & Negative & - & Enucleation & 16 , alive, NED & \\
\hline 6/Chinese & $M / 29$ & Body & Insulinoma & $1.5 \mathrm{~cm}$ & Negative & - & Distal pancreatectomy & 21, alive NED & \\
\hline 7/Chinese & $\mathrm{F} / 64$ & Tail & Malignant insulinoma & $7.0 \mathrm{~cm}$ & Positive & 1.4 & Distal pancreatectomy & $\begin{array}{l}\text { 15, alive with } \\
\text { residual disease }\end{array}$ & $\begin{array}{l}\text { Metastases in } \\
\text { liver }\end{array}$ \\
\hline 8/Chinese & $\mathrm{M} / 35$ & Tail & Insu & $1.5 \mathrm{cr}$ & $\mathrm{Neg}$ & - & createctomy & 11 , alive NED & \\
\hline 9/Chinese & $\mathrm{M} / 68$ & Head & Insulinoma & $1.0 \mathrm{~cm}$ & Negative & - & Enucleation & 4, alive, NED & \\
\hline 10/Chinese & $\mathrm{F} / 65$ & Head & Insulinoma & $1.5 \mathrm{~cm}$ & Negative & - & Enucleation & 3, alive, NED & \\
\hline
\end{tabular}

ACTH, adrenocorticotrophin; MEN 1, multiple endocrine neoplasia type 1; NED, no evidence of disease.

findings, and follow up data were noted from the clinical records. The preoperative localisation studies, biochemical investigations, hormonal studies, and postoperative follow up (radiological, biochemical, and hormonal investigations) were standardised for each patient.

\section{TELOMERASE ASSAYS}

Frozen tissue specimens were sectioned on a cryostat, and $10 \times 10 \mu \mathrm{m}$ thick sections from each specimen were resuspended in $200 \mu \mathrm{l}$ of ice cold lysis buffer. After 30 minutes incubation on ice, the lysate was centrifuged at $16000 \times g$ for 20 minutes at $4^{\circ} \mathrm{C}$. The supernatant was frozen in liquid nitrogen and stored at $-80^{\circ} \mathrm{C}$. The protein concentration of tissue extracts was determined by the BioRad protein assay (Hercules, California, USA).

Telomerase activity was assayed by the telomeric repeat amplification protocol (TRAP) method as described by Kim et al. ${ }^{7}$ Two protocols were used in our study: Telomerase polymerase chain reaction (PCR) enzyme linked immunosorbent assay (ELISA) (Boehringer Mannheim, Indianapolis, USA) and TRAP gel staining assay (Oncor, Gaithersburg, Maryland, USA).

In PCR ELISA, $5 \mu \mathrm{l}$ of tissue extracts (corresponding to 3-5 $\mu$ g total protein) was added to a final volume of $50 \mu \mathrm{l}$ of reaction mixture $(0.1 \mu \mathrm{g}$ TS primer (5'-AATCCGTCGAGCAGAGTT3'), $0.1 \mu \mathrm{g}$ CX primer (5'- CCCTTACCCTT ACCCTTACCCTTA-3'), $50 \mu \mathrm{M}$ dNTPs, and $2 \mathrm{U}$ Taq polymerase in $20 \mathrm{mM}$ Tris/ $\mathrm{HCl}$ buffer (pH 8.3)). A combined primer elongation/ amplification protocol was performed: (1) primer elongation: $25^{\circ} \mathrm{C}$ for 30 minutes; (2) telomerase inactivation: $94^{\circ} \mathrm{C}$ for five minutes; (3) amplification (for 30 cycles): $94^{\circ} \mathrm{C}$ for 30 seconds (denaturation), $50^{\circ} \mathrm{C}$ for 30 seconds (annealing), and $72^{\circ} \mathrm{C}$ for 90 seconds (polymerisation), followed by a final extension step at $72^{\circ} \mathrm{C}$ for 10 minutes. After PCR, $5 \mu l$ of the amplification product was treated with $20 \mu \mathrm{l}$ of denaturation solution for 10 minutes, and then transferred to $225 \mu \mathrm{l}$ of hybridisation buffer. Duplicate $100 \mu \mathrm{l}$ aliquots of the mixture were then added to a microplate precoated with streptavidin for capture of the biotinylated amplicons. After hybridisation for two hours at $37^{\circ} \mathrm{C}$, the plate was washed and horseradish peroxidase conjugated antidigoxigenin Fab antibody was added. TMB substrate solution (containing the peroxidase substrate, 3,3',5,5'tetramethyl benzidine) was used for colour development, and optical absorbance at 450 and $690 \mathrm{~nm}$ was measured using an ELISA reader (Molecular Devices, Sunnyvale, California, USA). Heat inactivated tissue extracts (subjected to 30 minutes treatment at $85^{\circ} \mathrm{C}$ before the TRAP assay) were used as telomerase negative controls and extracts prepared from papillary carcinoma of the thyroid (known to be positive for telomerase) were used as telomerase positive controls. ${ }^{8}$ Each reading represented the mean value of the $A_{450-690}$ (sample) minus the $\mathrm{A}_{450-690}$ (control). The criterion for a positive telomerase assay was an $\mathrm{A}_{450-690}$ of 0.2 or greater.

Alternatively, telomerase activity in tissue extracts was determined by the Oncor telomerase detection kit according to the manufacturer's instructions. The TRAP reaction product was analysed by electrophoresis in $0.5 \mathrm{M}$ Tris/ borate EDTA buffer on $12 \%$ polyacrylamide non-denaturing gels. The gels were soaked in Syber Gold solution for visualisation. A typical hexanucleotide ladder of three or more bands was observed in the telomerase positive lane. Results

Ten patients (six men, four women) with pancreatic endocrine tumours were studied. These comprised nine insulinomas and one tumour with documented ectopic adrenocorticotrophin (ACTH) production and carcinoid syndrome. Table 1 shows the clinicopathological characteristics and the results of the telomerase assay. The median age was 45 years (range, 29 to 64 ). The median size of the pancreatic endocrine tumours was $1.5 \mathrm{~cm}$ (range, 1 to 7 ). There appeared to be no correlation between tumour size and the results of the telomerase assay. In all the tumours, no significant lymphocytic infiltration was noted. Telomerase activity results were similar for both assays (PCR ELISA and TRAP silver staining assay). Telomerase activity was positive in the control tissue and three of 10 pancreatic endocrine tumours (fig 1).

Two patients presented with multiple liver metastases. One of them (a 43 year old woman) showed ectopic ACTH production and carcinoid syndrome. This patient also developed lung metastases and subsequently died of the 


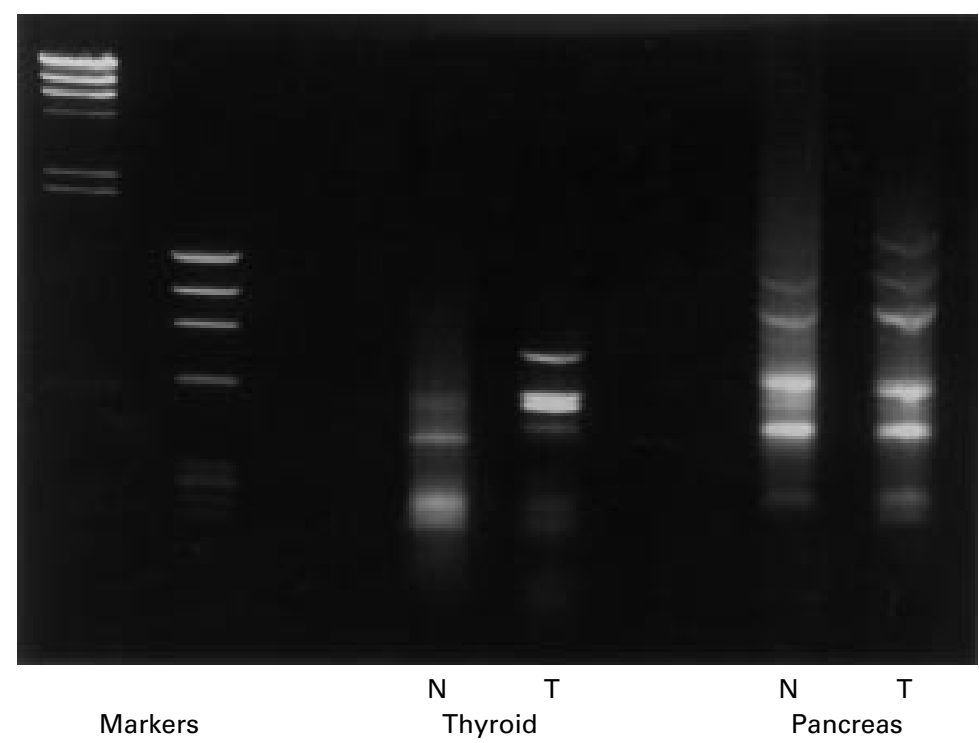

Figure 1 Telomerase activation can be observed in both the positive control (thyroid cancer) and one sample from a malignant endocrine tumour $(P) . N$, normal tissue; $T$, tumour tissue. activity from our tumour tissue bank. Telomerase activity was detected in three of the 10 pancreatic endocrine tumours. The telomerase positive tumours comprised two malignant pancreatic endocrine tumours with liver metastases and one insulinoma occurring in the setting of MEN 1. The telomerase positive tumour in the patient with MEN 1 was infiltrative and showed vascular and perineural tumour permeation. In addition, two of the three telomerase positive tumours were only $1 \mathrm{~cm}$ in diameter. Thus, telomerase was a potential marker for malignancy in pancreatic endocrine tumours and was positive even in malignant pancreatic endocrine tumours of small size.

A different surgical strategy is needed for the management of insulinomas in MEN $1 .{ }^{9}$ In our study, both patients with MEN 1 had multiple tumours in the pancreas. Telomerase activity was seen in the insulinoma in one patient but not in the other. Thus, telomerase activity did not distinguish the patients with or without MEN 1.

Telomerase activity has been demonstrated in benign or tumour adjacent somatic tissue samples. ${ }^{1}$ In some reports, telomerase activity in tissues resulted from the presence of activated lymphocytes. ${ }^{10}$ In our study, telomerase activity was noted in the morphologically non-neoplastic pancreas adjacent to the malignant pancreatic endocrine tumours, whereas no activity was detected in tissue next to benign lesions. No intense lymphocyte infiltration was present to account for the telomerase activity. The reason for this finding is unknown. The adjacent morphologically non-neoplastic tissue in malignant pancreatic endocrine tumours might be genetically unstable, or there might be microinvasion that escapes detection (in routine microscopy) in the adjacent nonneoplastic tissue to give rise to the presence of telomerase activity. Nevertheless, the study of telomerase activity in the non-tumorous tissue adjacent to the tumour might also help predict the malignant potential of pancreatic endocrine tumours.

Human cells in culture undergo a finite number of divisions, during which the length of telomeres declines and then the cells senesce. This stage can be averted by mutations in the tumour suppressor gene p53. ${ }^{1}$ Roos et al noted that telomerase activity in breast cancer was significantly associated with p53 overexpression. ${ }^{11}$ In some other cancers, no such relation was found. ${ }^{12}$ We have found no evidence of p53 accumulation in a study involving 52 pancreatic endocrine tumours (including the cases noted in our present study). ${ }^{14}$ Thus, no correlation was found between p53 overexpression and telomerase activity in pancreatic endocrine tumours. In addition, alternative mechanisms have been suggested for telomeric length stabilisation other than telomerase activation. ${ }^{15}$

In summary, our study suggests that telomerase expression does play a role in distinguishing between benign and malignant pancreatic endocrine tumours. On the basis of this preliminary study, documenting telomerase

In the present prospective study over a period of three years, we prospectively collected the tissues and analysed the telomerase 
assay as a marker for biological aggressiveness in pancreatic endocrine tumours should be investigated.

1 Soria JC, Vielh P, El-Naggar AK. Telomerase activity in cancer: a magic bullet or a mirage? Adv Anat Patho 1998;5:86-94.

2 Autexier C, Greider CW. Telomerase and cancer: revisiting the telomere hypothesis. Trends Biochem Sci 1996;21:387-91.

3 Lam KY, Lo CY. Pancreatic endocrine tumors: classical features and current insights. Cancer $\mathcal{F}$ 1998;11:18-26.

4 Lo CY, Lam KY, Kung AWC, et al. Pancreatic insulinomas: a 15-year experience. Arch Surg 1997;132:926-30.

5 Hiyama E, Kodama T, Shinbara K, et al. Telomerase activity is detected in pancreatic cancer but not in benign ity is detected in pancreatic cance
tumors. Cancer Res 1997;57:326-31.

6 Lam KY, Lo CY. Pancreatic endocrine tumor: a 22-year clinicopathologic experience with morphological, immunohistochemical observation and a review of the literature. Eur 7 Surg Oncol 1997;23:36

$7 \mathrm{Kim}$ NW, Piatyszek MA, Prowse KR, et al. Specific association of human telomerase activity with immortal cells and cancer. Science 1994;266:2011-15.
8 Lo CY, Lam KY. Telomerase activity in thyroid malignancy. Thyroid 1999;112:263-70.

9 Lo CY, Lam KY, Fan ST. Surgical strategy for insulinomas in multiple endocrine neoplasia type I. Am f Surg 1996;175:305-7.

10 Norrback KF, Dahlenborg K, Carlsson R, et al. Telomerase activation in normal B lymphocytes and non-Hodgkin's lymphomas. Blood 1996;88:222-9.

11 Roos G, Nilsson P, Cajander S, et al. Telomerase activity in relation to p53 status and clinicopathologic parameters in breast cancer. Int $\mathcal{F}$ Cancer 1998;79:343-8.

12 Brown T, Aldous W, Lance R, et al. The association between telomerase, p53 and clinical staging in colorectal cancer. Am $\mathcal{F}$ Surg 1998;175:364-6.

13 Oishi T, Kigawa J, Minagawa Y, et al. Alteration of telomerase activity associated with development and extension of epithelial ovarian cancer. Obstet Gynecol 1998;91:568-71

14 Lam KY, Lo CY. Role of p53 tumor suppressor gene in pancreatic endocrine tumors of Chinese patients. Am $\mathcal{F}$ Gastroenterol 1998;93:1232-5.

15 Greider CW. Telomerase activity, cell proliferation, and cancer. Proc Natl Acad Sci U S A 1998;95:90-2. 